\title{
FoRMADORES DE PROFESSORES DE FÍSICA: UMA ANÁLISE DE SEUS DISCURSOS E COMO PODEM INFLUENCIAR NA IMPLANTAÇÃO DE NOVOS CURRÍCULOS
}

\author{
Physics teachers' education: University Professors' \\ DISCOURSES AND THEIRS INFLUENCE IN THE IMPLEMENTATION OF A \\ NEW CURRICULUM
}

\author{
Beatriz S. C. Cortela \\ biacortela@fc.unesp.br \\ Roberto Nardi ${ }^{2}$ \\ nardi@fc.unesp.br
}

\section{Resumo}

Apresentam-se aqui resultados de uma pesquisa qualitativa, realizada com docentes universitários que atuam como formadores de professores, em um Curso de Licenciatura em Física de uma universidade pública no Brasil. A fim de atender às mudanças previstas pela legislação educacional, o corpo docente vem se reunindo com a finalidade de reestruturar o projeto pedagógico do curso. Buscando interpretar os discursos sobre os processos de ensino e aprendizagem e como estes podem influenciar nas decisões sobre a reestruturação curricular a ser proposta, esta pesquisa buscou verificar: 1) o grau de insatisfação com a estrutura atual do curso; 2) o comprometimento desses docentes frente ao processo de reestruturação; 3) a forma como organizam e desenvolvem sua prática docente; 4) suas principais dificuldades profissionais e 5) suas sugestões para a melhoria do ensino e, conseqüentemente, do curso em questão.

A interpretação dos discursos dos docentes mostra, por exemplo, que, embora vários deles atuem no ensino há mais de uma década, a maioria ainda posiciona-se como bacharéis na área, analisando o processo através de concepções de ensino e de aprendizagem oriundas do senso comum; admitem, conscientemente, suas limitações com relação aos conhecimentos pedagógicos e também, que o curso não está estruturado de forma que acreditam ser conveniente. Este e outros

Grupo de Pesquisa em Ensino de Ciências, Programa de Pós-Graduação em Educação para a Ciência. Faculdade de Ciências, UNESP, Campus de Bauru. 
resultados da pesquisa sugerem a necessidade de um processo de reflexão durante as atividades de reestruturação do curso, de modo que o perfil do professor de ensino médio a ser formado seja uma das primeiras preocupações para a construção do novo projeto pedagógico como também sejam aprofundados nesse novo currículo conteúdos relacionados com a Física Moderna e Contemporânea, História da Ciência e novas tecnologias.

Palavras-chave: formação de professores de Física, reestruturação curricular do Curso de Licenciatura em Física, concepções de professores de Física, análise do discurso.

\section{Abstract}

We describe here outcomes of a qualitative research undertaken among university professors, who teach physics in a undergraduate program intended to form future High School teachers (called Licenciatura) in a public university in Brazil. In order to attend the changes foreseen by the new national educational legislation, the faculty members have been studying ways to improve the pedagogical project of this program. Trying to interpret these professors' discourses on the teaching and learning processes and to understand how they can influence the decisions on the curricular reform to be proposed, this research tries to verify: 1) the commitment of these professors with the reform in the pedagogical and curricular structure of the program; 2) the way they organize and develop their teaching practice; 3) their main professional difficulties; 4) their suggestions to improve the teaching and, consequently, the program. The interpretation of the interviewed professors' discourses show that most of them poses like bachelors in physics, analyzing the process through teaching and learning conceptions arising from the commonsense. Other outcomes suggest the necessity of a collective reflection process during the activities for structure of the new program in order to consider as a focus the profile of the future High School teacher. Also, the broadening of the contents related do Modern and Contemporary Physics, History of Science and new technologies are demanded.

Keywords: Teachers' education, Physics Teaching Undergraduate Program Curricular Reform, Physics professors' conceptions, discourse analysis. 


\section{INTRODUÇÃO}

Apresentam-se aqui dados parciais de uma investigação que vem acompanhando o processo de reestruturação do projeto pedagógico de um curso de licenciatura em Física de uma universidade pública no Brasil. Esta reestruturação está sendo conduzida em função de dois fatores: atender às exigências das novas Diretrizes Curriculares para Formação de Professores no país (CNE/CP 9/2001) e, paralelamente, implantar o curso de bacharelado em Física nesta instituição, a partir de 2005.

O momento, portanto, é propício para a realização da investigação, que é de natureza qualitativa, aplicada, pois, visa encontrar resultados que possam ser diretamente utilizados na tomada de decisões práticas ou na melhoria e implementação de programas (Schein, 1987, apud Bogdan e Biklen, 1994: 264).

Buscando interpretar os discursos dos docentes sobre os processos de ensino e de aprendizagem e como estes podem influenciar nas decisões sobre a reestruturação curricular a ser proposta, esta pesquisa buscou verificar: 1) grau de descontentamento com a forma atual do curso; 2) o comprometimento desses docentes com o processo de reestruturação; 3) a forma como os docentes organizam e desenvolvem sua prática docente; 4) suas principais dificuldades profissionais e 5) suas sugestões para melhoria do ensino e, conseqüentemente do curso em questão.

A partir dos discursos dos docentes sobre a forma como organizam e desenvolvem suas práticas pedagógicas, pôde-se interpretar suas concepções sobre ensino e aprendizagem, sistematizou-se o que eles pensam a respeito de seu trabalho, de seus alunos e das mudanças que estão sendo propostas. Os discursos também propiciaram interpretar suas posições, permitindo avaliar até que ponto os docentes estão preparados -ou mesmo, dispostos- a refletirem sobre suas práticas docentes, em função da implantação das novas propostas curriculares.

Além da interpretação dos discursos que refletem as posições dos docentes entrevistados, a análise desse processo poderá ser importante para a implantação destes projetos pedagógicos, bem como a de outros processos semelhantes, uma vez que "... o trabalho dos investigadores não é sempre o de avaliar, mas também o de descrever e comentar aquilo que se passa." (Bogdan e Biklen,1994: 277).

Esta análise é necessária, pois não são simplesmente novas estruturas curriculares que devem garantir as mudanças esperadas na formação de professores. É preciso lembrar que as mudanças curriculares procuram refletir o "espírito da lei" a que estão atreladas. As reformas ocorrem, entre outros fatores, para que os objetivos que a referida lei defende sejam efetivados. Por sua vez, o Estado, em sua forma política, representa uma determinada 
classe social, que é detentora do poder naquele momento histórico. Assim, ele representa os interesses desta classe dominante e defende suas ideologias. Em relação à legislação educacional, pode-se dizer que [...] ela é um veículo adequado para fazer com que os processos educacionais concretizem os valores da ideologia que se quer transmitir (Severino,1986: 56).

Quando a dominação de uma classe por meio de leis é substituída pela representação ou por idéias de que essas leis são legítimas, justas, boas e válidas para todos, temos a ideologia. A ideologia é o processo pelo qual as idéias da classe dominante tornam-se idéias de todas as classes sociais, tornando-se idéias dominantes (Chaui, 2001: 84).

A atual Lei de Diretrizes e Bases (Lei 9394/96), LDB, procurou propiciar uma identidade ao Ensino Médio, uma vez que a anterior (Lei 5692/71) o havia descaracterizado. Ela determina que o Ensino Médio é a etapa final da Educação Básica (Art. 36), sendo assim parte integrante da formação para o exercício da cidadania, mínimo necessário para que as pessoas possam ter acesso às atividades produtivas a fim de prosseguirem seus estudos em níveis mais elevados, propiciando meios para progredirem no mundo do trabalho.

Os currículos do ensino fundamental e médio devem ter uma base nacional comum (Art. 26) e ela traz, em si, a dimensão de preparação para o trabalho e também para o prosseguimento dos estudos, buscando priorizar o desenvolvimento de "habilidades e competências" básicas e não o acúmulo de algoritmos para a resolução de problemas pré-estabelecidos. Os algoritmos devem fazer parte de um conhecimento maior, qual seja, o de explicitar numa linguagem simbólica, toda uma série de conceitos e generalizações. Estes termos assinalados, assim como outros presentes nestes documentos, nem sempre têm o mesmo significado para os professores. $E$ a forma como eles estão sendo compreendidos, ou não, faz diferença na implantação de um modelo educacional que está sendo proposto.

Esta atual LDB foi implantada após um longo período de ditadura militar no Brasil e de posterior abertura política, já na chamada "era da globalização", na qual os processos de construção de conhecimentos e tecnologias vêm sendo acelerados. Isso exige dos profissionais das diversas áreas, habilidades como adaptação a novas situações, resolução de problemas, capacidade de trabalhar em equipe, atualização contínua, entre outras. Assim, o profissional está sempre em formação, tendo que se capacitar continuamente.

O lema educacional desta LDB é formar o cidadão-trabalhador-estudante. Essa aprendizagem inclui, além dos conhecimentos específicos de cada profissão, a ética, a autonomia intelectual e a compreensão dos processos científicos e tecnológicos envolvidos na produção de bens e tecnologias. Também houve um crescente movimento, no sentido de colocar (e fazer permanecer) na escola fundamental e média, o maior 
número possível de alunos; a implantação de classes de aceleração; a progressão continuada e a proposta da inclusão de alunos com necessidades especiais. Estas e outras medidas governamentais adotadas modificaram as relações de trabalho e passaram a exigir mudanças de paradigmas nas concepções sobre ensino e aprendizagem.

Para que os alunos possam desenvolver todas as competências e habilidades citadas nos Parâmetros Curriculares Nacionais (PCN), como: capacidade de abstração; desenvolvimento do pensamento sistêmico; capacidade de trabalhar em equipe; disposição para aceitar críticas, entre outras, o Estado, através de seus representantes, determinou que se faz necessário redimensionar a formação de professores que irão atuar no ensino fundamental e médio. Assim, as universidades e instituições de ensino superior são vistas como importantes parceiras na responsabilidade pelo êxito destas Diretrizes Curriculares para o Ensino Médio.

Um dos maiores desafios para a área de Ciências, segundo os Parâmetros Curriculares Nacionais (PCN), é a formação adequada de professores e elaboração de materiais instrucionais apropriados. Por formação adequada deve-se entender não apenas uma exigência maior sobre a cultura científica, mas deve haver uma mudança na postura do professor, deixando de ser a de detentor do saber e passar a ser crítico-reflexivo, orientador-pesquisador do apren- dizado de seus alunos, buscando aprimorar a contextualização e a interdisciplinaridade.

Além dos parâmetros curriculares em nível nacional, as propostas curriculares da área de Ciências, em nível de secretarias estaduais de educação, apresentam princípios metodológicos muito parecidos: usar o cotidiano e os conhecimentos prévios dos alunos como ponto de partida; levar em conta o contexto históricosocial; usar a natureza como laboratório; proporcionar uma metodologia de ensino ativa; promover a interdisciplinaridade; favorecer uma visão globalizante da ciência; discutir as relações entre ciência, tecnologia e sociedade.

Sendo o trabalho docente algo individual e coletivo simultaneamente, e que não se encerra ao final de um ciclo, ele faz parte de um projeto educacional e todo projeto educacional é necessariamente um projeto político e não há como evitá-lo (Severino,1986: XIV). Assim, da mesma forma que o educador deve ter, como todo profissional, uma habilitação técnica fundamentada nos conhecimentos científicos, no domínio dos conteúdos que vai ministrar, no uso de métodos e técnicas de ensino; ele também precisa ter uma formação política e filosófica. Precisa se ver como membro de uma sociedade, em um certo momento histórico. E esta é também uma função da universidade: dar-lhe noção de consciência social, como sustenta a atual LDB (Art. 43, III e IV). 


\section{A Pesquisa}

Diversos autores mostram que os professores, em todos os níveis de ensino, desde o fundamental ao universitário, deixam suas influências nos futuros docentes. Sobre essa questão Camargo (2003), ao investigar as marcas deixadas pelos professores deste mesmo curso de licenciatura ora estudado nos discursos dos alunos de Prática de Ensino em Física, afirma que aquelas deixadas pelos professores das disciplinas específicas estão mais evidentes na forma como os alunos ministram suas aulas durante o estágio supervisionado, do que aquelas deixadas pelos docentes das disciplinas pedagógicas. Ou seja, eles podem "aprender" a ministrar suas aulas utilizando-se diversas metodologias, mas, ao executá-las, utilizam-se de formas de ensino mais tradicionais.

Por esta razão optou-se, nesta pesquisa, por ouvir os docentes que ministram as disciplinas específicas, estabelecendo um protocolo de entrevistas, abarcando quatro eixos de questionamentos: suas histórias profissionais, suas concepções sobre ensino e aprendizagem, as metodologias de ensino que utilizam em suas aulas e o que sabem e/ou gostariam que fosse mudado na reestruturação do curso de licenciatura em Física.

Optou-se pelo uso das entrevistas, visando interpretar os discursos dos docentes universitários, uma vez que, quando o sujeito está sendo entrevistado, ele acaba inserindo-se em formações discursivas típicas de uma determinada classe, ao utilizar de um vocabulário próprio, ideologias e outras marcas que permitem ao pesquisador perceber (em função do que está sendo proposto) o que ele sabe, analisa e critica, a respeito dos assuntos investigados. Os investigadores qualitativos buscam analisar os dados em toda sua extensão e não os recolhem com o objetivo de confirmar ou não hipóteses previamente estabelecidas. As abstrações vão sendo construídas à medida que os dados vão sendo recolhidos e agrupados. O instrumento para a recolha de dados foi a entrevista semiestruturada, gravada em áudio. Esta escolha permite a análise da fala, ou do discurso do entrevistado e existe a certeza de se obter dados comparáveis, entre os vários sujeitos participantes da pesquisa.

Foram ouvidos onze dos trezes docentes do Departamento de Física, que atuam como formadores de professores na licenciatura em questão. Cada entrevista durou, em média, quarenta minutos. Estas ocorreram de outubro de 2002 a junho de 2003. O protocolo da entrevista procurou abarcar quatro eixos de questionamentos: a história profissional do docente, suas concepções sobre ensino e aprendizagem, as metodologias de ensino que utiliza em suas aulas, o que sabe e/ou o que acha das mudanças que estão sendo propostas para a reestruturação do curso em questão. 


\section{A análise dos dados. Análise do Discurso (AD)}

A análise dos dados recolhidos foi conduzida através de técnicas de Análise do Discurso (em adiante AD). Existem várias linhas de AD: a usada neste trabalho foi aquela desenvolvida no Brasil por Orlandi (2002) e Brandão (1997), a partir dos estudos de M. Pêcheux; a chamada linha francesa. Orlandi considera que existem diferentes maneiras de se estudar a linguagem: a Lingüística, a Gramática e a Análise do Discurso. Quando se estuda a língua, enquanto sistema de signos ou como sistemas formais, tem-se a Lingüística; quando, no foco de interesse estão as normas de bem dizer, temos a Gramática; quando se tenta compreender a língua fazendo sentido, enquanto um trabalho simbólico, como parte do trabalho social, temse Análise do Discurso (AD).

Assim, a $A D$ não trabalha a língua enquanto sistema abstrato, mas, como forma de significar o mundo; com homens falando, tanto como sujeitos quanto membros de uma sociedade, estando fato, história e sociedade numa relação de dependência. Partindo da idéia de que a materialidade específica da ideologia é o discurso, e que a materialidade específica do discurso é a língua, a AD trabalha a relação língua-discurso-ideologia. (Orlandi, 2002).

Quando os estudiosos passam a buscar a compreensão da linguagem, não mais centrados apenas na língua (considerada um sistema ideologicamente neutro), mas buscando a real significação de um texto em condições sócio-históricas, aí é que ocorre a AD. A linguagem, enquanto discurso, não é formada apenas de signos, que sevem para comunicação ou suporte para o pensamento. Ela é uma interação e uma produção social; não é neutra e nem natural. $O$ que caracteriza a $A D$ é a "posição" do locutor: a relação entre quem fala, o que fala e o mundo.

A escola francesa de AD se caracteriza por apresentar uma articulação entre a lingüística, o marxismo e a psicanálise, sendo foco de preocupação de lingüistas, historiadores e psicólogos, numa base interdisciplinar. (Maingueneau, 1987, apud Brandao, 2002: 17).

Dois conceitos tornam-se nucleares para AD: o de ideologia e o de discurso. Na linha francesa, valem os conceitos de Althusser, do lado da ideologia; e os de Foucault, para o discurso. Para Althusser, a escola é responsável pela inculcação da ideologia dominante, através do conhecimento e valores que transmite. É um meio de reprodução de forças vigentes na sociedade e a educação procede ideologicamente em dois níveis: enquanto processo, pois transmite e reproduz conteúdos culturais, impondo-os às classes dominadas; enquanto ideologia pedagógica ou sistema de pensamento, que tem por objetivo camuflar, através de um discurso articulado, as reais relações de violência material e simbólica. (Severino, 1986: 48) 
Para Foucault, o discurso é uma família de enunciados que pertencem a uma mesma formação discursiva. As formações discursivas são aquelas que determinam o que pode e o que deve ser dito numa determinada situação. Como as palavras possuem posições ideológicas, as formações discursivas fazem parte das formações ideológicas. Palavras iguais podem ter significados diferentes uma vez que se inscrevem em formações discursivas distintas.

Formações ideológicas são integradas por um conjunto de atitudes e representações que não são individuais, mas que estão relacionadas com as posições de classes em conflito. Nelas, os silêncios são tão importantes quanto às falas dos sujeitos: quando se diz, por exemplo, "sem medo", ao invés de "com coragem", há um silenciamento constitutivo e o sujeito está escolhendo uma forma de representação de idéias que não é neutra e nem ingênua. Muitas vezes, o sujeito não diz o que quer dizer, pois há uma censura: ocorre um silenciamento local. Um silêncio pode ser muito significativo quando, por exemplo, expressa determinadas idéias ou fatos.

Segundo Orlandi (2002), o analista do discurso não é um hermeneuta: ele trabalha nos limites da interpretação. Ele não se coloca fora da história, da ideologia. Ele se coloca numa posição deslocada que the permite contemplar (encarar, pensar sobre) o processo de produção dos sentidos. Apesar de a análise não ser objetiva, ela deve ser o menos subjetiva possível, explicitando o modo de produção de sentidos do objeto de observação.
Um dos primeiros pontos a se considerar para a análise dos dados é a construção do corpus. Sua delimitação não segue critérios empíricos (positivistas), mas teóricos. O corpus está intimamente ligado à análise, pois, quando se decide o que vai fazer parte do corpus, já se está decidindo acerca das propriedades discursivas, uma vez que, quando se organiza o material, leva-se em conta a pergunta, o ponto de vista de quem o organiza.

Com o material bruto coletado fazse uma análise lingüística: quem disse, o quê disse, como disse, buscando pistas que explicitem como o discurso está contextualizado, uma vez que seus autores deixam vestígios no fio do discurso. Orlandi (2002: 65) chama isso de-superficialização. O objetivo é procurar construir, a partir do material bruto (a transcrição da entrevista), um objeto discursivo para então interpretar o que é dito nesse discurso e o que é dito em outros, em diferentes condições, afetados por diferentes memórias discursivas.

Como o objeto do discurso não é dado, o material bruto deve ser trabalhado pelo analista. Para tanto, deve-se converter o corpus bruto, o dado empírico, em um discurso concreto, em objeto lingüisticamente desuperficializado. Então, pode-se começar a analisar a discursividade, que se desenvolve por meio do raciocínio dedutivo.

Para tanto, deve-se observar o modo com que o texto analisado foi construído, sua estruturação, as diferentes leituras feitas, buscando nos vestígios deixados, analisar e inter- 
pretar. Quando o analista passa do corpus bruto para o objeto discursivo e deste para o processo discursivo, ele mostra o trabalho da ideolo- gia: os efeitos da língua na ideologia e a materialização desta na língua. Com isso, apreende a historicidade do texto.

\section{INTERPRETAÇÃO DOS DADOS: ALGUMAS ANÁLISES}

O protocolo de entrevista abarcou quatro eixos de questionamentos: a história profissional do sujeito; suas concepções sobre ensino e aprendizagem. as metodologias de ensino adotadas em suas aulas; seus conhecimentos à respeito da reestruturação proposta ou o quê gostaria que fosse mudado no curso de licenciatura atual.

Partindo do pressuposto de que as concepções sobre ensino e aprendizagem dos professores formadores e suas metodologias de ensino estão relacionadas, o estudo procurou organizá-las. Tendo em vista que esta reestruturação proposta tem como objetivo, dentre outros, de adequar o projeto pedagógico desta licenciatura às recomendações expressas na LDB e nas Diretrizes Curriculares Nacionais, é importante verificar nos discursos dos docentes que conhecimentos têm sobre expressões e termos empregados nos documentos, como as "competências" e "habilidades" para o exercício da docência; sobre o papel do professor em sala de aula, contidos nos PCN e nas novas Diretrizes para a Formação de Professores do MEC/ SESU (Brasil, 2002).

Cada entrevista foi analisada integralmente. Primeiro foram feitas as notas de campo, chamadas de Comentários do Observador, que buscam aproximar o leitor do campo de observação do pesquisador e das condições de produção do discurso. Depois, foram feitas as transcrições das entrevistas, para que o leitor possa fazer a "sua" interpretação das falas dos sujeitos. Seguem as análises das falas e dos não-ditos e a explicitação do discurso do professor, segundo a interpretação da pesquisadora: são as marcas do discurso, o que está implícito na fala do sujeito, a posição de onde ele fala.

Como o primeiro passo, em direção às mudanças é estar insatisfeito com o atual modelo -ou a forma como está sendo aplicado-, estes docentes se mostram descontentes? Caso seja verdade, eles se julgam preparados para efetuarem estas mudanças? Concordam que aquelas propostas pelos documentos oficiais sejam as esperadas por eles? Quais as competências que gostariam que seus alunos desenvolvessem ao longo do curso? Como estão trabalhando em suas aulas? Quais suas dificuldades docentes? O quê sabem a respeito dos documentos que estão subsidiando as discussões sobre a reestruturação? 


\section{Algumas respostas encontradas}

Os docentes entrevistados fazem algumas críticas ao modelo de estrutura curricular atualmente vigente (entre 2002-2003). Entre elas, destacam-se a ausência de um trabalho coletivo; a forma como o curso está estruturado, muito parecido com um curso de bacharelado; a forma, ainda muito quantitativa, como que os conteúdos continuam a ser trabalhados, visando mais a aquisição de algoritmos de resolução, que o desenvolvimento dos conceitos físicos propriamente ditos; que faltam ser trabalhados conteúdos ligados à Física Moderna e Contemporânea, à Ciência, à Tecnologia e a Astronomia, entre outros.

A maioria dos docentes se diz descontente com a formação oferecida aos seus alunos da licenciatura e se diz disposta a fazer mudanças. No entanto, não se julgam preparados pedagogicamente para ministrar suas aulas utilizando-se de vários recursos didáticos ou fazendo uso de outros modelos de ensino diferentes do tradicional.

Todos os docentes entrevistados citaram que o domínio dos conhecimentos específicos é a primeira competência a ser desenvolvida neste profissional. Quanto a isso, a maioria dos entrevistados acredita que o atual modelo de estrutura curricular está sendo eficiente, bastando fazer alguns ajustes para o que o currículo fique melhor.

Utilizam-se de metodologias tradicionais; fazem uso de livros clássicos, que usaram em suas graduações; poucos elaboram o próprio material didático; utilizam-se de instrumentos e critérios de avaliação tradicionais (classificatórios). Muitos admitem que repetem o modelo de ensino com que aprenderam.

De uma maneira geral não realizam nenhum trabalho coletivo, seja na elaboração das ementas, nem tampouco durante o desenvolvimento do projeto de pedagógico do curso, que sequer foi citado pelos entrevistados. Afirmam que esta forma solitária de trabalho é comum e não questionada pela maioria dos docentes deste departamento.

A maioria dos professores admite sentir dificuldades com os conteúdos pedagógicos; em contextualizar os conteúdos que ministram e também em utilizar a História da Ciência em suas abordagens.

A respeito dos documentos que estão embasando as reestruturações, pôde-se concluir que nenhum dos sujeitos admitiu ter analisado os PCN; poucos admitiram que os leram; em suas falas, pouco aparece de seu vocabulário ou de suas intenções. Sobre as Diretrizes Curriculares para Formação de Professores, as falas estão bastante desencontradas, revelando que existem várias dúvidas, decorrentes de diversas interpretações. Em relação à atual LDB, pôde-se perceber que, em suas falas não aparecem seus objetivos, somente parte de sua ideologia. 
Esta pesquisa, como já foi dito no início deste trabalho, faz parte de um projeto maior que é o acompanhamento do processo de reformulação de um currículo de licenciatura em Física em uma das unidades de uma universidade pública. No entanto, ela poderá contribuir também para as reestruturações e discussões que estão ocorrendo, ou vão ocorrer, em outras escolas, uma vez que os estudos feitos durante este trabalho levam a crer que esta seja uma situação comum em outras universidades brasileiras. Sendo assim, esperase que ela possa somar-se a outras pesquisas, com a finalidade de propiciar subsídios que levem a uma melhoria na qualidade de ensino oferecida, não só nesta unidade, em particular.

\section{ReferênCIAS}

Bogdam e Biklen. (1994) Investigação Qualitativa em Educação: uma introdução à teoria e aos métodos. Coleção Ciências da Educação. Porto: Porto Editora.

Brandão, H.H.N. (1997) Introdução a Analise de Discurso. 6 ${ }^{\mathrm{a}}$ ed. Campinas: Editora da Unicamp.

Diário Oficial da União. Lei 9394 de 20 de dezembro de 1996. Estabelece as Diretrizes e Bases da Educação Nacional. de 23 de dezembro de 1996.

Ministerio da Educação do Brasil (1999). Parâmetros Curriculares Nacionais: Ensino Médio. Secretaria da Educação Média e Tecnológica, Brasília, Ministério da Educação.

Brasil. Parecer CNE/CP 9/2001, de 8 de maio de 2001. Diretrizes Curriculares Nacionais para a Formação de Professores de Educação Básica em nível superior. Curso de licenciatura, de graduação plena.

Brasil. Resolução CNE/CP1/2002, de 18 de fevereiro de 2002. Institui Diretrizes $\mathrm{Cu}$ rriculares Nacionais, para a formação de professores de Educação Básica, em nível superior, curso de licenciatura, de graduação plena. Diário Oficial da União, Brasília, 9 de abril de 2002. Seção 1, p. 31.

Camargo, S. (2003) Prática de Ensino de Física: marcas de referenciais teórico no discurso de licenciandos. Dissertação (Mestrado em Educação para a Ciência).Universidade Estadual Paulista, Bauru.

Chaui, M. (2001) O que é ideologia. $2^{\mathrm{a}} \mathrm{ed}$. São Paulo: Brasiliense.

Cortela, B.S.C. (2004) Formadores de Professores de física: uma análise de seus discursos e como podem influenciar na implantação de novos currículos. Dissertação (Mestrado em Educação para a Ciência). Faculdade de Ciências. Universidade Estadual Paulista, UNESP. Campus de Bauru.

Orlandi, E.P. (2002) Análise do discurso: Princípios e Procedimentos. $4^{\mathrm{a}}$ ed. Campinas, SP: Pontes.

Sandoval, J.S. e Cudmani, L. C. (1993). Epistemología e Historia de la Física en la Formación de los Profesores de Física. Revista Brasileira de Ensino de Física.

Severino, A.J. (1986) Educação, ideologia e contra-ideologia. São Paulo: EPU. 